\title{
Adaptations of a native Subantarctic flightless fly to dehydration stress: more plastic than we thought?
}

\author{
Short Communication
}

\author{
Isabel C. Barrio ${ }^{1,2^{*}}$, David S. Hik ${ }^{1}$, Maryvonne Charrier ${ }^{3}$, Yves Frenot ${ }^{4}$, \\ David Renault ${ }^{3}$ \\ ${ }^{I}$ Department of Biological Sciences, University of Alberta, Edmonton, Canada \\ ${ }^{2}$ Pyrenean Institute of Ecology (CSIC), Jaca, Spain \\ ${ }^{3}$ Université de Rennes 1, UMR CNRS 6553 EcoBio, Rennes, France \\ ${ }^{4}$ Institut Polaire Français Paul Émile Victor, Technopôle Brest-Iroise, Plouzané, France
}

\begin{abstract}
Water conservation is a critical aspect affecting the survival, distribution and abundance of terrestrial arthropods. In this study we investigate mechanisms of dehydration tolerance of the native, flightless fly, Calycopteryx moseleyi, inhabiting contrasting environments at two localities in the Kerguelen Islands. We compare the survival abilities and management of body water content of adult flies from two different ecophenotypes when exposed to conditions of low relative humidity. Our results suggest a broad plasticity in the responses of $C$. moseleyi to desiccation, showing distinct local adaptations to environmental conditions.
\end{abstract}

Key words: Calycopteryx moseleyi, Pringlea antiscorbutica, desiccation, Kerguelen Islands, survival, water balance

DOI: $10.5817 / \mathrm{CPR} 2014-2-12$

\section{Introduction}

Physiological plasticity allows adaptation to different environmental conditions, and is critical for the persistance of species endemic to rapidly changing ecosystems, such as Subantarctic terrestrial ecosystems. Water availability is one of the main challenges for invertebrates inhabiting polar regions, because liquid water is biologically unavailable for most of the year, and many polar arthropods have developed adaptations to cope with dehydration (Chown et al. 2011). Basically, there are three non-exclusive mechanisms through which invertebrates can cope with hydric stress: storing water, being more tolerant to water loss, and/or reducing water loss. Desiccation tolerance is thus often measured by monitoring changes in body water content. We studied a flightless fly, native to

Received October 15, 2014, accepted December 29, 2014.

*Corresponding author: Isabel C Barrio <icbarrio@gmail.com>

Acknowledgements: Funding for this project was provided by the Institut Polaire Français PaulÉmile Victor (IPEV Programme 136) and the Natural Sciences and Engineering Research Council (Canada). Special thanks are due to D. Ertz and M. Hullé for assistance in the field and in the lab. 
the Kerguelen Islands, Calycopteryx moseleyi, to investigate local adaptations to dehydration stress. Calycopteryx moseleyi is able to exploit two contrasting environments, differring in their relative humidity (RH) and salinity (Laparie et al. 2012, this study): the axils of the leaves of the native Kerguelen cabbage (Pringlea antiscorbutica; $~ 80 \%$ $\mathrm{RH}$, non-saline conditions) and decomposing seaweeds in rocky seashores $(\sim 60 \% \mathrm{RH}$ and salinity of up to 70 parts per thousand). Populations of $C$. moseleyi inhabiting each of these habitats have distinct molecular and morphological adaptations, in particular with relation to saline stress, resulting in two distinct ecophenotypes (Laparie et al. 2012). Meanwhile, their ability to tolerate dehydration stress and capacities of underlying physiological mechanisms remain largely unknown. Our investigation of local adaptations of the two ecophenotypes of $C$. moseleyi to dehydration stress focused on three main aspects: bulk body water stores, ability to tolerate and resist desiccation, and rates of water loss. In this study, we expected differences in the way the two ecophenotypes cope with dehydration stress, with increased body water contents and tolerance to dehydration in flies from seaweeds (the more stressful, drier environment).

\section{Material and Methods}

Calycopteryx moseleyi (Micropezidae, Diptera) is a flightless fly endemic to the subantarctic Kerguelen and Heard islands (Greenslade et al. 2012). Although the main habitat of this species is thought to be the native Kerguelen cabbage, it inhabits environments of contrasting characteristics. Previous studies have focused on ecophysiological adaptations to salinity (Laparie et al. 2012, Renault et al. 2014).

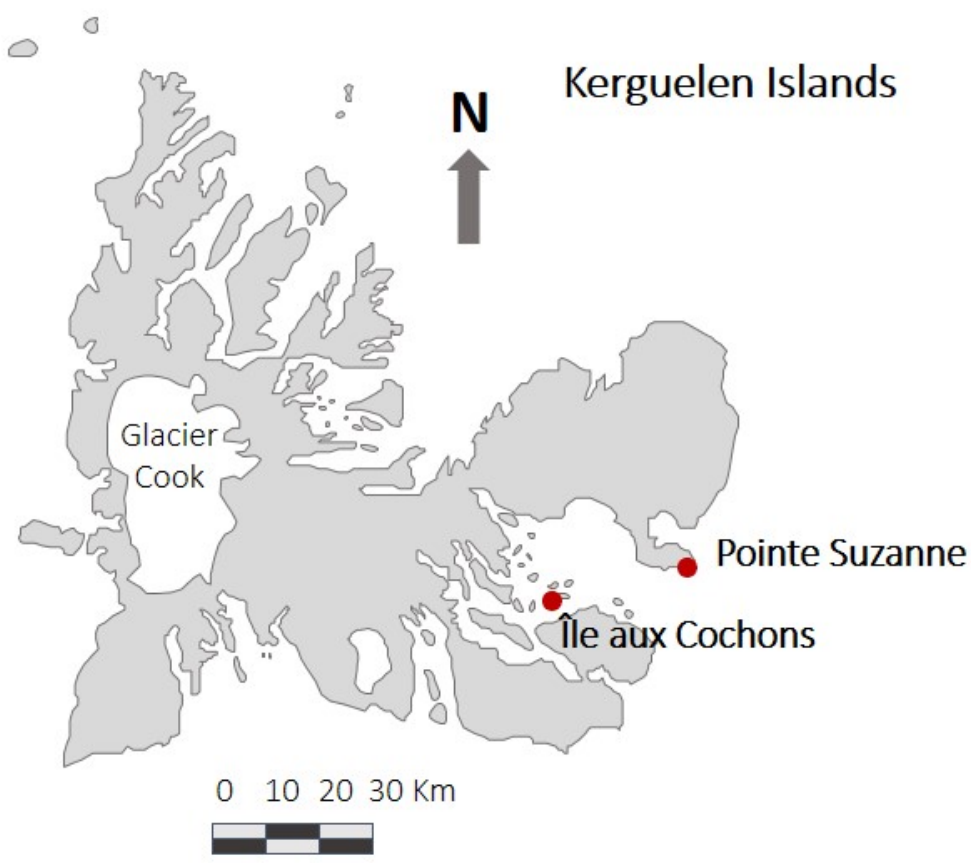

Fig. 1. Location of the collection localities in the Kerguelen Islands. 
Flies from two ecophenotypes, seaweeds and Kerguelen cabbages, were collected from two localities at the Kerguelen Islands (49 $\left.26^{\prime} \mathrm{S}, 70^{\circ} 26^{\prime} \mathrm{E}\right)$ : Pointe Suzanne and Ile aux Cochons (Fig. 1). Flies were raised under controlled, low (10\%-40\%) and ambient $(65 \%) \mathrm{RH}$ conditions in the lab, after thermal and humidity acclimation of the insects to standard (experimental control) conditions $\left(7^{\circ} \mathrm{C}, 65 \% \mathrm{RH}\right)$ for $1-3$ days. To investigate potential differences in the way the two ecophenotypes cope with dehydration stress, we assessed:

- Body water content, expressed as a percentage of initial mass, was calculated as the difference between initial fresh mass and dry mass (after oven-drying specimens for three days at $60^{\circ} \mathrm{C}$ ) of flies under ambient conditions. All specimens were weighed using a Sartorius ${ }^{\circledR}$ analytical balance (A200S-F1, precision $0.1 \mathrm{mg})$.

- Dehydration tolerance was calculated as the percentage of total body water lost until death by desiccation at very low RH (<10\%; Gibbs et al. 1997).

- Desiccation resistance was measured as survival time to lethal dehydration of flies under low $(40 \% \mathrm{RH})$ and control $(65 \% \mathrm{RH})$ humidity conditions. Accumulated mortalities over the first three days were calculated for each locality and ecophenotype.

- Changes in body water content over time were analysed for flies collected at Pointe Suzanne, incubated at low $(40 \% \mathrm{RH})$ or control $(65 \% \mathrm{RH})$ humidity conditions. Flies of each ecophenotype from each experimental condition were sampled at one-hour intervals ( 1 to $6 \mathrm{~h}$ ) and reweighed. To further evaluate changes in body water content over longer periods of time, samples were also taken following the same protocol at 24, 48, 72 and $96 \mathrm{~h}$. The rate of water loss was derived from the slope of the regression line on a plot of $\operatorname{Ln}\left(\mathrm{m}_{\mathrm{t}} / \mathrm{m}_{0}\right)$, where ' $\mathrm{m}$ ' is body water content, against the duration of exposure (Wharton 1985, Aggarwal et al. 2013) and is expressed as the proportion of body water lost per hour.

Data were analysed using Linear Models (LM), including the interaction between ecophenotype and locality as predictor variable in the models for body water content and dehydration tolerance, and the three-way interaction between ecophenotype, experimental manipulation of RH ( $40 \%$ or control) and time for modelling the rates of water loss over time (Table 1). Non-significant interactions were dropped from the final models. Accumulated mortalities were compared using paired t-tests. Statistical analyses were performed in R 3.0.1 (R Development Core Team 2014).

\section{Results and Discussion}

Overall, the two ecophenotypes differed in their responses to dehydration stress, but traits related to water balance management were more similar than expected. Ecophenotypes differed in fresh body mass, with flies living under seaweeds being heavier $(20.35 \pm 5.74 \mathrm{mg})$ than those from cabbages $(16.63 \pm 6.19 \mathrm{mg} ; \mathrm{LM}, \mathrm{t}$ value $=7.157$, 
$\mathrm{p}=0.000$ ), but body mass differences did not translate into larger body water storages for seaweed fly populations. Percentages of body water content ranged between $62-84 \%$ and were similar across ecophenotypes (Table 1a), but differed for the two sampling locations (Ile aux Cochons $77.4 \pm 4.6 \%$, Pointe Suzanne $71.9 \pm 4.9 \%$ ). Differences in body mass between populations of $C$. moseleyi inhabiting contrasting habitats have been previously reported (Laparie et al. 2012), but seem unrelated to body water content. Mechanisms other than bulk water storage, such as metabolic water storage (Gibbs et al. 1997) or behavioural avoidance (Jury et al. 1994), may account for differences in the response to dehydration stress of the two ecophenotypes and require further investigation.

Dehydration tolerance differed for the two ecophenotypes and sampling locations (Table 1b; Fig. 2A); flies from seaweeds were more sensitive to water loss, tolerating losses of up to $45 \%$ of total body water ( $v s 57 \%$ in cabbage flies). This is an unexpected finding, but consistent with higher accumulated mortalities observed for seaweed populations over the first three days (paired t-test, $t=-3.284, p=0.006 ;$ Fig. 2B). Rates of water loss at low humidity (40\%) increased over time, and were consistently higher for flies exposed to low humidity conditions relative to controls (Fig. 3). Water loss differred between ecophenotypes only initially ( $1 \mathrm{hr}$ after the start of the experiment; $\mathrm{F}=8.524, \mathrm{p}=0.019$; Table 1c) and was higher for the cabbage ecophenotype, but declined and remained similar thereafter.

\begin{tabular}{|c|c|c|}
\hline & F-value & p-value \\
\hline \multicolumn{3}{|l|}{ a) Body water content } \\
\hline Location & 8.777 & 0.006 \\
\hline Ecophenotype & 1.441 & 0.240 \\
\hline \multicolumn{3}{|l|}{ b) Dehydration tolerance } \\
\hline Location & 9.488 & 0.003 \\
\hline Ecophenotype & 6.142 & 0.016 \\
\hline \multicolumn{3}{|l|}{ c) Changes in body water content } \\
\hline Ecophenotype*RH*time & 14.975 & 0.000 \\
\hline
\end{tabular}

Table 1. Results of Linear Models (LM) for each of the mechanisms related to water balance: a) initial body water content (percentage of initial weight), b) dehydration tolerance, and c) changes in body water content.

\section{Conclusion}

Our results suggest a high plasticity for dehydration-related traits in C. moseleyi. Understanding how native invertebrates cope with stress and their ability to adapt to local environmental conditions can help predict the persistence of wild populations in sensitive terrestrial Subantarctic ecosystems. 
A) Dehydration tolerance

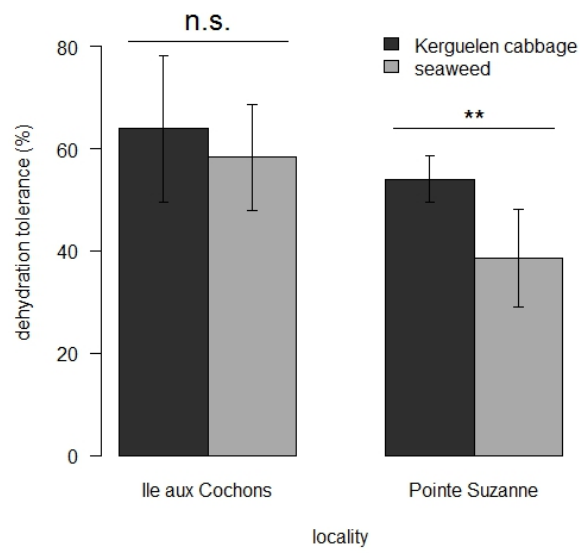

B) Accumulated mortality at $40 \% \mathrm{RH}$

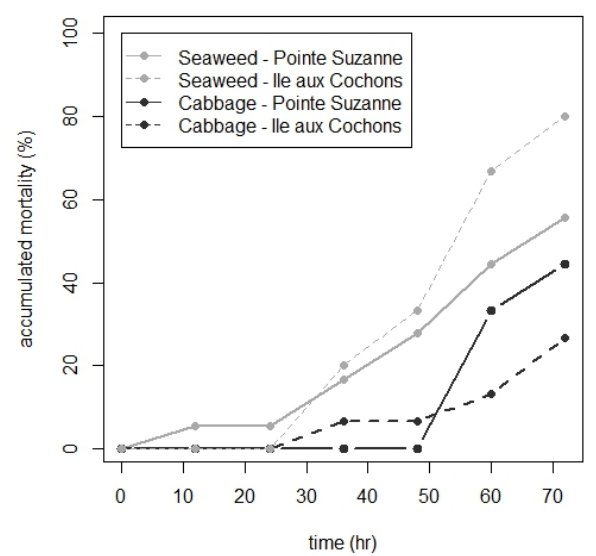

Fig. 2. Dehydration tolerance and accumulated mortality at low RH in adult Calycopteryx moseleyi inhabiting Kerguelen cabbages or decaying seaweeds, from two sampling localities, Ile aux Cochons and Pointe Suzanne. A) Dehydration tolerance represents the percentage of total body water lost prior to death at very low humidity $(10 \%)$. Means and standard errors are shown; statistical differences (n.s. non-significant, ' $* *$ ' $p<0.01$ ) between populations within each location are indicated. B) Accumulated mortality (\%) of flies exposed to low humidity ( $40 \% \mathrm{RH})$ during 72 hours.

\section{Rates of water loss}

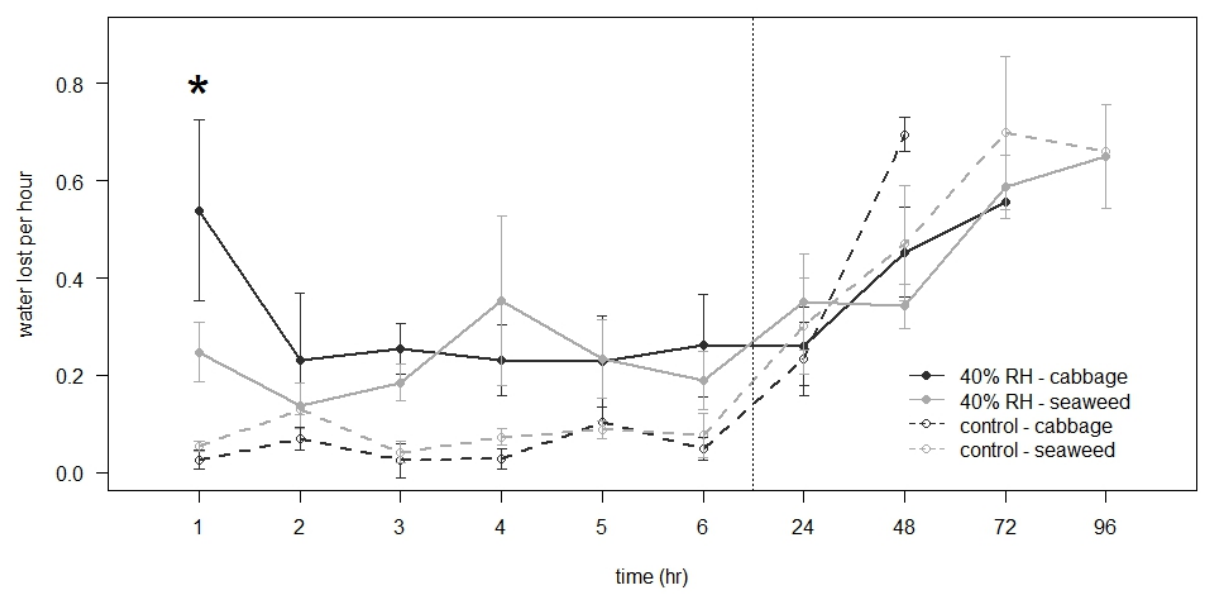

Fig. 3. Rates of water loss (proportion of body water lost per hour) in flies from Pointe Suzanne every hour at the beginning of the experiment (1-6 hr) and every 24 hours over a longer time period (to the right of the vertical dotted line). Asterisks indicate significant differences $(p<0.05)$ between flies from cabbages (dark grey) and seaweed (light grey) exposed to low humidity conditions ( $40 \%$; solid lines) and ambient (control) humidity conditions (dashed line). 
I. C. BARRIO et al.

\section{References}

Aggarwal, D. D., Ranga, P., Kalra, B., Parkash, R., Rashkovetsky, E. and Bantis, L. E. (2013): Rapid effects of humidity acclimation on stress resistance in Drosophila melanogaster. Comparative Biochemistry and Physiology, Part A, 166: 81-90.

Chown, S. L., Sørensen, J. G. and Terblanche, J. S. (2011): Water loss in insects: An environmental change perspective. Journal of Insect Physiology, 57: 1070-1084.

Gibbs, A. G., Chippindale, A. K. and Rose, M. R. (1997): Physiological mechanisms of evolved desiccation resistance in Drosophila melanogaster. Journal of Experimental Biology, 200: 1821-1832.

Greenslade, P., Vernon, P. and Smith, D. (2012): Ecology of Heard Island Diptera. Polar Biology, 35: 841-850.

JuRY, S. H., KinNison, M. T., Howell, W. H. and WATSON III., W. H. (1994): The behavior of lobsters in response to reduced salinity. Journal of Experimental Marine Biology and Ecology, 180: 23-37.

Laparie, M., Bical, R., Larvor, V., Vernon, P., Frenot, Y. and Renault, D. (2012): Habitat phenotyping of two sub-Antarctic flies by metabolic fingerprinting: evidence for a species outside its home? Comparative Biochemistry and Physiology. Part A, 162: 406-412.

Renault, D., Lombard, M., Vignere, J. and LAPARIE, M. (2014, in press): Comparative salinity tolerance in native flies from the subantarctic Kerguelen Islands: a metabolomic approach. Polar Biology, DOI: 10.1007/s00300-014-1605-8.

Wharton, G. W. (1985): Water balance of insects. In: G. A. Kerkut and L. I. Gilbert (eds): Comprehensive Insect Physiology, Biochemistry and Pharmacology. Pergamon Press, Oxford. pp. 563-603.

\section{Other sources}

R Development Core Team. (2014): R: A language and environment for statistical computing. R Foundation for Statistical Computing, Vienna, Austria. 